\title{
Peculiarities of Injection Molding Conducting Composites
}

\author{
Yovial Mahyoedin ${ }^{1 *}$, Jaafar Sahari ${ }^{2}$, Andanastuti Mukhtar ${ }^{2}$, Norhamidi Mohammad $^{2}$, Iqbal $^{1}$ \\ ${ }^{1}$ Department of Mechanical Engineering, Bung Hatta University, Indonesia \\ ${ }^{2}$ Department of Mechanical and Material Engineering, Universiti Kebangsaan Malaysia, Malaysia.
}

\begin{abstract}
The investigations in this study focused on the characteristic of feedstock in an effort to understand the mechanism of injection molded in composite material. A composite, which has $75 \%$ wt. filler, consist of graphite $(\mathrm{G})$, carbon black (CB) and polypropylene copolymer (PP). Twinscrew co-rotating extruder used for mixing materials. The conductivity of the molded parts measured using a four-point probe test procedure. The results showed that the injection molding conducting composites, which aggregated into larger clusters, tended to disperse unevenly into the PP, resulting in fewer particle-particle contacts and, consequently, a lowerconductivity composite in some part of the molded.
\end{abstract}

\section{Introduction}

As it was well explained by percolation theory, the electrical properties of polymer composite mainly depend on the dispersion condition of filler particles, particle size and aggregate structure [1]. Whilst, injection molding is one of the preferred methods for manufacturing parts of thermoplastic polymers. However, the main difficulty of using injection molding is its inability to handle materials with poor flow characteristics since the highest the viscosity the more difficult materials to be injected [2]. One characteristic for injection-molded parts is an anisotropic character in structure and, thus, properties due to molecular chains and filler particles orientation resulting from high processing velocities. If the melt is cooled down rapidly to ensure short cycle times, these orientations are frozen and remain in the molded part. In the case of conductive filler particles having a high aspect ratio, such as CNT, orientations lead to an impairment of network formation and, thus, to a shift of the percolation threshold towards higher filler contents [3, 4].

This paper reports the injection molding study on the characteristics of polymer composites based on graphite and carbon black as fillers in order to produce an electrical conducting composite material.

\section{Material and Methods}

An granular polypropylene (PP) random copolymer grade TitanPro SM 688 from Titan Petchem Sdn. Bhd, was selected as matrix phase (binder) for the different composite

\footnotetext{
*Corresponding author : jmahyoedin@yahoo.com
} 
formulations. Two type of conductive filler; supplied by Asbury Graphite Mills, Inc, were investigated in this study, i.e. natural graphite $(\mathrm{G})$ type Asbury 3243 and carbon black (CB) type Asbury 5303. Table 1 illustrated the properties of these materials.

Table 1. Material properties.

\begin{tabular}{lcccc}
\hline \multicolumn{1}{c}{ Material } & $\begin{array}{c}\text { Density } \rho \\
(\mathrm{g} / \mathrm{cm} 3)\end{array}$ & $\begin{array}{c}\text { Conductivity } \sigma \\
(\mathrm{S} / \mathrm{cm})\end{array}$ & $\begin{array}{c}\text { Melting Point } \\
\left({ }^{\circ} \mathrm{C}\right)\end{array}$ & $\begin{array}{c}\text { Particle size } \\
\mathrm{D}_{50}\end{array}$ \\
\hline Polypropylene & 0.905 & $8.50 \mathrm{E}-14$ & $\sim 170$ & \\
Carbon Black & 0.918 & 341 & & $11.5 \mu \mathrm{m}$ \\
Graphite & 1.28 & 33.4 & & $56.4 \mu \mathrm{m}$ \\
\hline
\end{tabular}

The sampels for this study were formed using Injection Molding machine type Arburg Allrounder 850-210-320 D. Injection nozzle with diameter of $3 \mathrm{~mm}$ used to ensure smooth flow of material into the cavity.

The electrical conductivity characteristics of injection-molded composite are significantly affected by the distribution of filled conducting fibers. Moreover, the particles distribution is influenced by the injection molding processing parameters. Hence, by properly controlling molding process conditions, the filler conductive polymer can be arranged to have a higher electrical conductivity value with the aim of bipolar plate. Therefore, Taguchi optimization technique was applied to identify the optimal settings of control factors which would acquire the greatest electrical conductivity value of plates.

The injection molding process of conductive composite were conducted, after optimizations on the compound material, the injection molding process (e.g. the process parameters) and the molding tool using taguchi method. Plates of $100 \mathrm{~mm} \times 50 \mathrm{~mm}$ with thickness $2.0 \mathrm{~mm}$ were produced successfully by injection molding. The process cycle time for each plate only takes between 20 and $50 \mathrm{~s}$.

Finally, the electrical conductivity of plates in the in-plane direction was measuring using four point probe type Jandel Sensitive Digital Voltmeter.

\section{Results and Discussion}

\subsection{Filler Material.}

Mixture materials to injection molding shall have the uniformity and have the appropriate of electrical conductivity as well. According to percolation study, uniformity is also can improve the electrical conductivity of the mixture materials.

A combination of fine and coarse filler particles lead to higher electrical conductivity which might be attributed to the higher maximum packing fraction of the filler powders [5]. Table 2 showed distribution of particle size and particles shape of both fillers. Large values of the distribution slope $\mathrm{Sw}$ correspond to narrow particle size distributions and small value corresponds to broad distributions.

Table 2. Particle size distribution and cumulative particle sizes

\begin{tabular}{lccccc}
\hline \multicolumn{1}{c}{ Filler powder } & $\begin{array}{c}\text { Shape } \\
\text { particle }\end{array}$ & $\begin{array}{c}\mathrm{D}_{10} \\
(\mathrm{~mm})\end{array}$ & $\begin{array}{c}\mathrm{D}_{50}(\mathrm{~mm}) \\
\text { Average size }\end{array}$ & $\begin{array}{c}\mathrm{D}_{90} \\
(\mathrm{~mm})\end{array}$ & $\mathrm{S}_{\mathrm{W}}$ \\
\hline Natural graphite (NG 3243) & flakes & 18.586 & 56.435 & 127.089 & 3.066 \\
Carbon black (CB 5303) & particles & 3.922 & 11.585 & 66.225 & 2.085 \\
\hline
\end{tabular}

The result showed that both filler particles are suitable for injection molding process, since $S_{W}$ values of both material is quite small and close enough to 2 (the easier filler powders to mold exhibit $\mathrm{S}_{\mathrm{W}}$ value of 2). Large values of distribution slope $\mathrm{S}_{\mathrm{W}}$, correspond to narrow 
particle size distribution and small values correspond to broad distribution [6]. This result also showed that graphite powder seem more difficult to mold when compare to carbon black. From the shape particles view, graphite also seems more difficult to mold because of flakesshaped. It is well known that spherical particles tend to easier molding and afford of high solids loading.

\subsection{Injection Molding Process}

An injection-molded plate of $100 \mathrm{~mm} \times 50 \mathrm{~mm}$ was divided into several areas for measuring electrical conductivity. Figure 1 shows the measurement areas. The samples tested were derived from the results of taguchi optimization with a composition of $20 \% \mathrm{PP}-80 \% \mathrm{G} / \mathrm{CB}$.
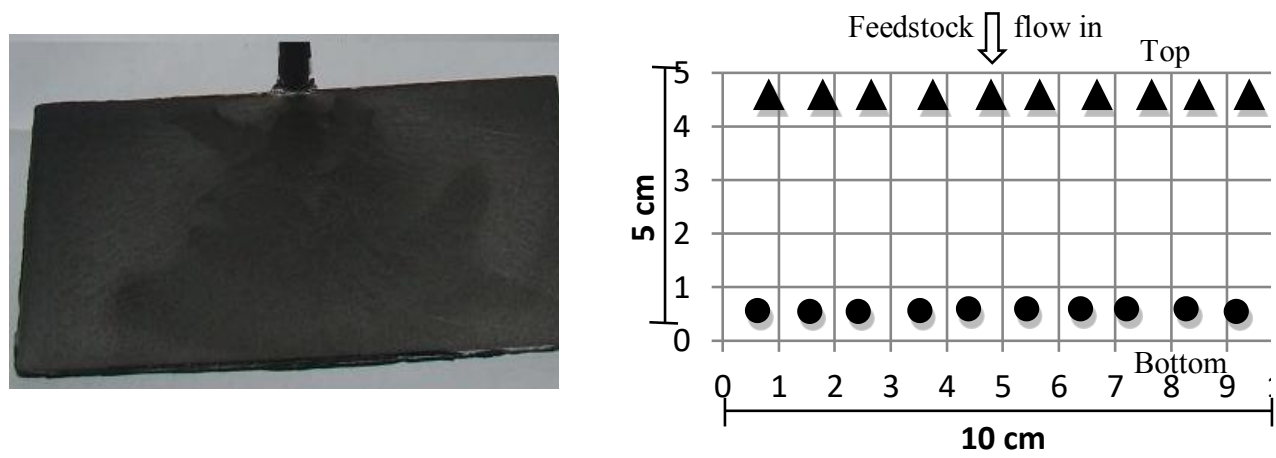

Fig. 1. a) Injection molding sample. b) Electrical conductivity measurements area

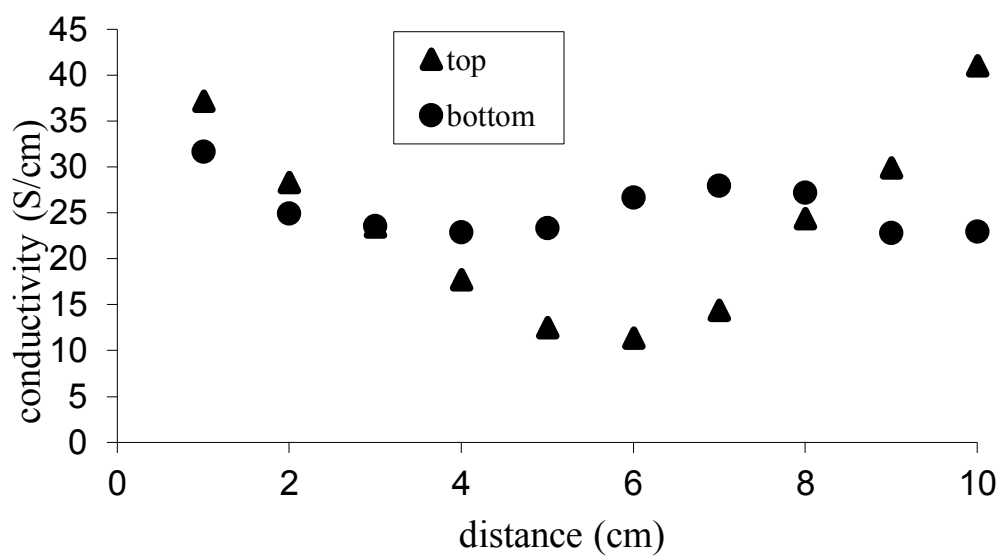

Fig. 2. Electrical conductivity of injection molding sample $20 \% \mathrm{PP}: 80 \% \mathrm{G} / \mathrm{CB}(90 \%$ Gnat $+10 \% \mathrm{CB})$

Figure 2 shows the measured electrical conductivity on the surface of the sample with a composition of $20 \%$ PP- $80 \%$ G/CB. Results show that the conductive filler tended to disperse more evenly near the wall of cavity, thereby resulting in many particle-particle contacts and, consequently, a higher-conductivity polymer composite. Whereas, the lower conductivity value was found in the center part of the sample. This suggest that there is significant anisotropy was displayed in the $\mathrm{PP} / \mathrm{G} / \mathrm{CB}$ composites (i.e. particles are randomly oriented in the matrix) thus providing a non-uniform electrical conductivity value within the plate. 
However, processing of composite at low filler loading will result in filler-matrix separation when subjected to high pressure during molding. This indicates at high-filler loading the separation does not occur, thus caused non-uniform filler within the plate. Further, it seems that the flow of filler material into the cavity was not completely proper and, consequently, has great significant in predicting the electrical conductivity of final parts. Non-uniform distribution of filler also causes the electrical conductivity of the material becomes non-uniform. Reduced the amount of filler in the middle of the plate causes the electrical conductivity of materials in part also decrease as shown in Figure 3.

The viscosity of the feedstock was influenced greatly by the shear strain rate and temperature of the feedstock. The viscosity of the dispersed system filled with fine particles is also strong influenced by the degree of agglomeration of the particle in the system. As the concentration of the particles increases, in general, the ability to form agglomerates increases, thus the electrical conductivity also increase. Meanwhile, the forming of agglomerates increases the effective concentration on viscosity of the system, because the volume fraction of the liquid occluded by the agglomerates, that is, the liquid volume that is not responsible for the viscosity, increases as the size of agglomerates increases

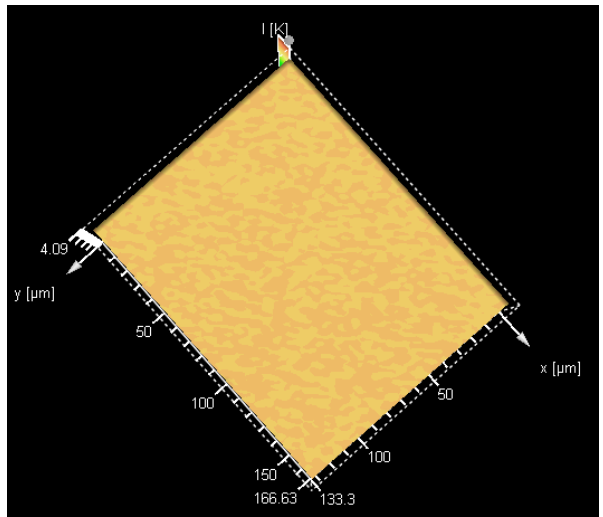

(a)

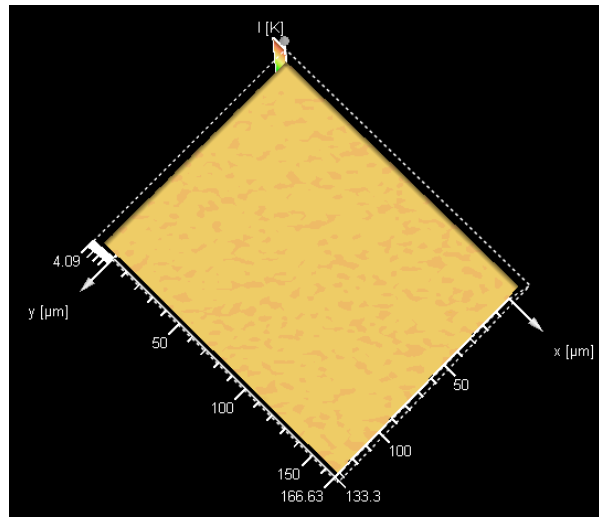

(b)

Fig.3. infrared micrographs of filler material. (a) near the wall. (b) center part

\section{Conclusion}

In this paper, we studied the injection molding process for the production of electrically conductive composite material. High viscosity, in line with higher filler contents, which results in poor flowing of materials, are not the only drawback to using injection molding in producing polymer composite. Non uniform electrical conductivity values of final parts are common outcomes as well.

It has been stressed that homogeneous composite, which contains the maximum filler loading and without sacrificing the ease of molding, should be used in the injection molding mixing step as this will maximize electrical conductivity. Hence, from this study, composite with filler loading of $20 \mathrm{wt} \% \mathrm{CB}$ was the most suitable filler loading.

The authors would like to thank The Ministry of Higher Education for their financial support of this work through Fundamental Research Grants under UKM-RF-02-FRGS 650001-2007 


\section{References}

1. Jing X. Z. W., Lan L. Journal of Mat Sci Letters, 19:377- 379 (2000)

2. Heinzel, A., Mahlendorf, F., Niemzig, O., Kreuz, C., J. Power Source, 131: 35-40 (2004).

3. Weber M, Kamal MR. Polymer Compos. 18(6):711-25 (1997)

4. T. Villmow, S Pegel, Petra P., Udo W. Composites Science and Technology. 68 777-789 (2008)

5. Kalyon, D.M., Birinci, E., Yazici, R., Karuv, B. \& Walsh, S. Poly Eng and Sci. 42(7): 1606. (2002)

6. Yovial M, Jaafar S, Andanastuti M, Norhamidi M., Advanced Materials Research. 233 2353057 (2011). 